\title{
An analysis of an inflammatory bowel disease practice in an urban community hospital
}

\author{
David Adam Bsc ${ }^{1}$, Jonathan Adam $\mathrm{BSc}^{2}$, Howard Price MD FRCPC ${ }^{3}$
}

\begin{abstract}
D Adam, J Adam, H Price. Analysis of an inflammatory bowel disease practice in an urban community hospital. Can J Gastroenterol 2000;14(6):483-488.
\end{abstract}

OBJECTIVES: To review an individual community gastroenterologist's experience with inflammatory bowel disease (IBD). The aspects studied were distribution of disease, need for hospital admission, immunosuppressants, systemic steroids, and surgery and its indications. The incidence of cancer was also reviewed.

PATIENTS AND METHODS: The charts of all IBD patients $(n=373)$ seen between 1993 and 1996 by an individual gastroenterologist in an urban community hospital were reviewed for the aforementioned information. Patients seen during this period may have been diagnosed with IBD before or during the period of 1993 to 1996.

RESULTS: Of the 373 patients, 219 had Crohn's disease (CD) and 154 had ulcerative colitis (UC). The most common age of onset for both groups was 20 to 29 years. Distal UC and distal Crohn's colitis patients rarely required surgery, hospitalization, systemic steroids or immunosuppressants. Eighty per cent of patients with small bowel CD and $51 \%$ of those with ileocolonic $\mathrm{CD}$ required at least one operation. Of the UC patients, $10.4 \%$ required surgery. Of the UC patients undergoing surveillance for cancer, none developed cancer but one developed significant dysplasia.

CONCLUSIONS: In both CD and UC the site of the inflammation plays a major role in determining the need for hospitalization, surgery, systemic steroids and immunosuppressants. Distal UC, the most common form of UC in this group of patients, is a very benign disease. Of all forms of IBD, small bowel CD had the greatest need for hospitalization, surgery and systemic steroids.

Key Words: Community hospital; Crohn's disease; Hospital admissions; Inflammatory bowel disease; Operations; Ulcerative colitis

\section{Entéropathies inflammatoires - analyse de la pratique dans un hôpital communautaire en milieu urbain}

OBJECTIF : Examiner l'expérience d'un gastro-entérologue rattaché à un hôpital communautaire à l'égard des entéropathies inflammatoires (EI). Ont fait l'objet d'analyse la répartition de ces affections, les hospitalisations, l'immunosuppression, les stéroïdes par voie générale, la chirurgie et ses indications, de même que l'incidence du cancer.

PATIENTS ET MÉTHODE : On a passé en revue le dossier médical de tous les patients atteints d'une EI $(\mathrm{n}=373)$ ayant consulté un gastroentérologue en particulier entre 1993 et 1996 dans un hôpital communautaire en milieu urbain. Le diagnostic d'EI peut avoir été posé durant la période visée ou avant.

RÉSULTATS : Deux cent dix-neuf des 373 patients vus en consultation souffraient de la maladie de Crohn (MC) et 154, d'une rectocolite ulcérohémorragique (RUH). L'âge le plus fréquent d'apparition de la maladie dans les deux groupes se situait entre 20 et 29 ans. Les patients atteints d'une RUH ou d'une colite de Crohn distales ont rarement eu besoin de chirurgie, d'hospitalisation, de stéroïdes par voie générale ou d'immunosupresseurs. Quatre-vingts pour cent des patients porteurs d'une MC du petit intestin et $51 \%$ de ceux qui étaient porteurs d'une $\mathrm{MC}$ iléo-colique ont subi au moins une opération. Des patients atteints de RUH, 10,4 \% ont eu besoin d'une intervention chirurgicale, et aucun de ceux qui ont été suivis pour dépistage du cancer n'a été victime de la maladie, mais on a observé un cas de dysplasie importante.

CONCLUSION : Le site d'inflammation joue un rôle déterminant en ce qui concerne les hospitalisations, la chirurgie, les stéroïdes par voie générale et les immunosuppresseurs, et ce, tant pour la MC que pour la RUH. La RUH distale, la forme la plus fréquente de la maladie dans le groupe de patients à l'étude, s'est avérée une maladie bénigne. De toutes les formes d'EI, la MC du petit intestin est celle qui a nécessité le plus d'hospitalisations, d'interventions chirurgicales et de stéroïdes par voie générale.

\footnotetext{
${ }^{1}$ Faculty of Medicine, University of Toronto, Toronto, Ontario; ${ }^{2}$ Faculty of Dentistry, State University of New York, Buffalo, New York, USA

${ }^{3}$ Department of Medicine, University of Toronto, Active staff - Centenary Hospital, Scarborough, Ontario

Correspondence: Dr H Price, 1371 Neilson Road, Scarborough, Ontario M1B 4Z8. Telephone 416-281-9552, fax 416-281-6242

Received for publication June 29, 1998. Accepted April 9, 1999
} 
Tnflammatory bowel disease (IBD), comprising Crohn's 1 disease (CD) and ulcerative colitis (UC), remains one of the most difficult conditions to manage for practising gastroenterologists. Because a definitive cure for IBD is still not available, treatments focus on alleviating symptoms through pharmacotherapy and surgical procedures.

Although most publications regarding concepts of IBD diagnosis and management stem from tertiary care university hospitals, the vast majority of IBD patients are treated by community gastroenterologists. Therefore, providing insight into the relative severity of symptoms and probability of surgery in a community IBD population may be helpful to the practitioner in providing information to IBD patients as to the probable course of their disease.

A retrospective chart review of patients with IBD seen by an experienced gastroenterologist in a community hospital was undertaken. The parameters reviewed included category and site of disease, age of onset, duration of disease, the need for surgical intervention and its indications, hospital admissions, prescription of immunosupressants, courses of systemic steroid treatment and the complication of cancer. These variables were related to the type of IBD (CD or UC) as well as to the location of the disease in the gastrointestinal tract.

\section{PATIENTS AND METHODS}

Charts were selected for review based on several criteria. Patients must have been seen at least once between 1993 and 1996. However, the initial diagnosis of IBD may have been made before this time period. Moreover, the patient's entire history (before and including the aforementioned time span) was included in the data. Patients were followed after consultation, ensuring accurate and up to date files.

Endoscopic and/or radiological diagnosis of IBD as CD or $\mathrm{UC}$ was made according to accepted guidelines (1-3). The authors' five cases of indeterminate colitis were not included in the study. Patient parameters were analyzed by location of disease.

UC patients were separated into three classes - distal (involvement of the rectum, with or without the sigmoid), leftsided (to the splenic flexure) and pancolitis.

CD was divided into four classes - distal colitis, ileocolonic disease, small bowel only and proximal colitis. 'Distal' referred to the rectum and sigmoid only (ileocolonic and small bowel are self explanatory) and 'proximal colitis' referred to inflammation of the colon proximal to the sigmoid (and at times including the rectum plus or minus the sigmoid).

The need for hospital admission and number of operations throughout the course of the patient's illness were determined. Surgery required for perianal abscesses and fistulas were not included in these surgical statistics. When an operation was needed, the indication for surgery was recorded. Courses of systemic steroids that were prescribed were recorded for each subclassification of disease.

Treatment of patients with immunosuppressants was classified as either 'effective' or 'not effective'. The 'not effective' group comprised patients whose symptoms did not improve with treatment and patients who had to cease the therapy

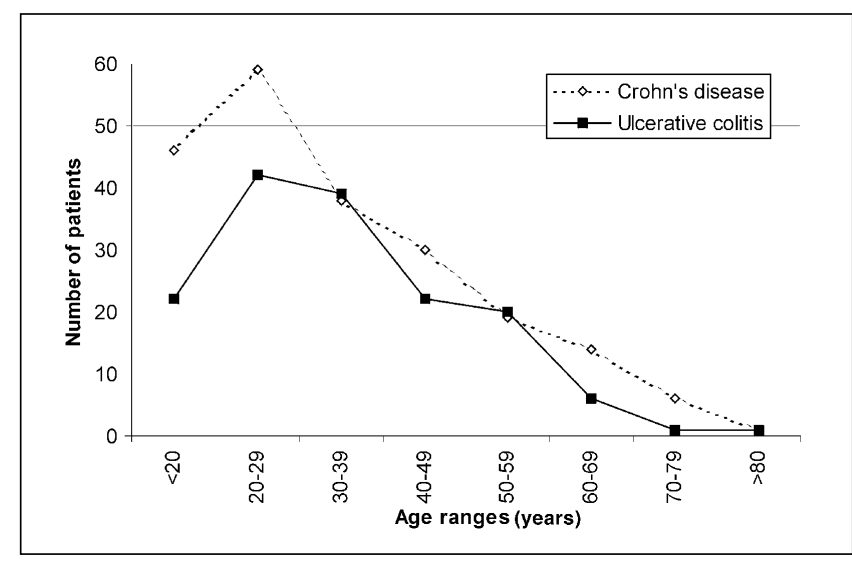

Figure 1) Comparison of the age of onset of Crohn's disease with that of ulcerative colitis

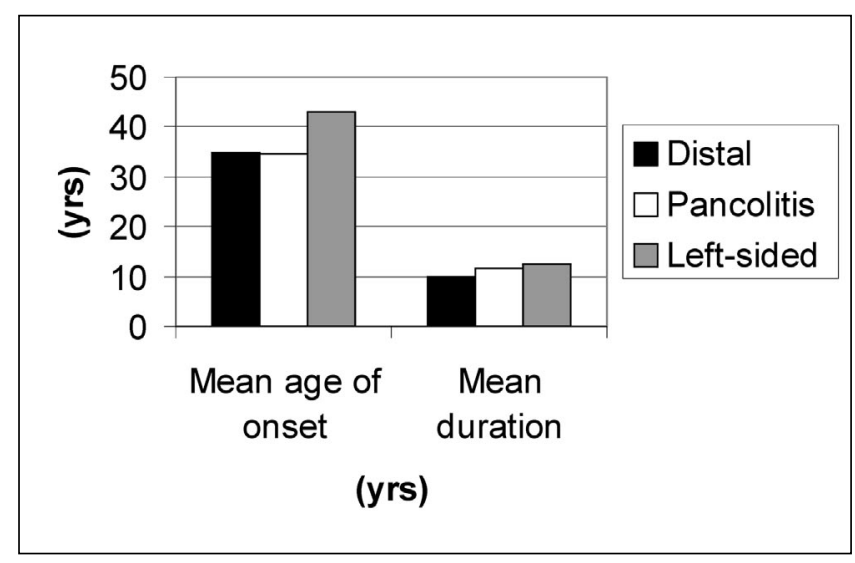

Figure 2) Mean age of onset and mean duration of disease in patients with ulcerative colitis, classified by location in the gastrointestinal tract. Yrs Years

due to adverse reactions. The 'effective' classification comprised patients whose symptoms improved with treatment. The immunosuppressants prescribed were one of 6mercaptopurine, azathioprine or methotrexate.

Cancer surveillance was performed via colonoscopy on all patients who had either left-sided UC or pancolitis for 10 years or more.

\section{RESULTS}

Upon review of the charts $(n=373)$ the breakdown of $C D$ and UC was 219 and 154, respectively. Of the UC patients, 77 were male and 77 female. Of the CD patients, 90 were male and 129 female. No deaths occurred during the course of the study. The age of onset for both diseases peaked in the 20- to 29-year range (Figure 1). The median and mean ages of onset in each subclassification were calculated and differed by an average of 1.6 years. This indicates that the distribution of ages within each subclassification is not significantly skewed in either direction. The mean and median duration of disease were also calculated, and similar results were obtained. The values for mean age of onset and mean duration of disease are summarized in Figure 2 for UC 


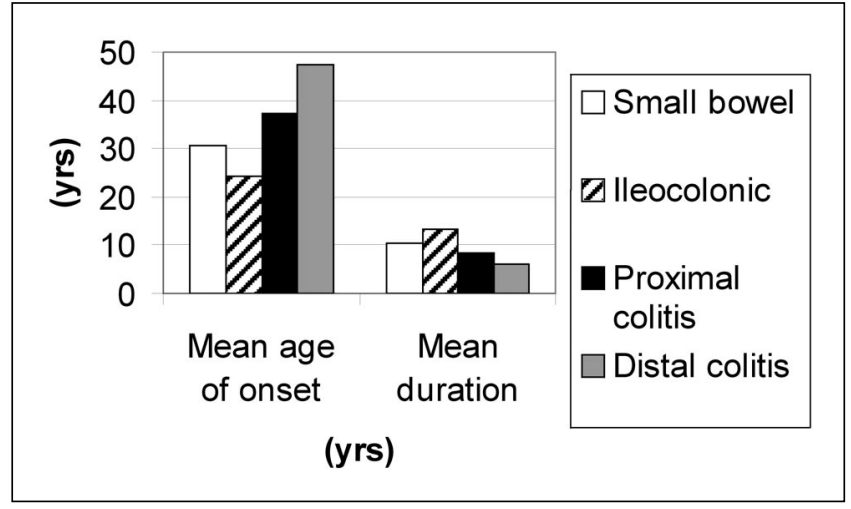

Figure 3) Mean age of onset and mean duration of disease in patients with Crohn's disease, classified by location in gastrointestinal tract. Yrs Years

TABLE 1

Ranges in values for the age of onset and duration of disease in patients with ulcerative colitis

Location of disease

\begin{tabular}{lrcc} 
& Distal & Pancolitis & Left-sided \\
\hline Age of onset, range (years) & $13-68$ & $14-69$ & $20-85$ \\
Duration, range (years) & $1-48$ & $1-35$ & $3-30$ \\
\hline
\end{tabular}

TABLE 2

Ranges in values for the age of onset and duration of disease in patients with Crohn's disease

\begin{tabular}{lcccc}
\hline & \multicolumn{4}{c}{ Location of disease } \\
& $\begin{array}{c}\text { Small } \\
\text { bowel }\end{array}$ & lleocolonic & $\begin{array}{c}\text { Proximal } \\
\text { colitis }\end{array}$ & $\begin{array}{c}\text { Distal } \\
\text { colitis }\end{array}$ \\
\hline Age of onset, range & $12-70$ & $9-50$ & $10-83$ & $16-79$ \\
(years) & $1-25$ & $1-37$ & $1-35$ & $1-27$ \\
$\begin{array}{c}\text { Duration, range } \\
\text { (years) }\end{array}$ & $1-27$ & & \\
\hline
\end{tabular}

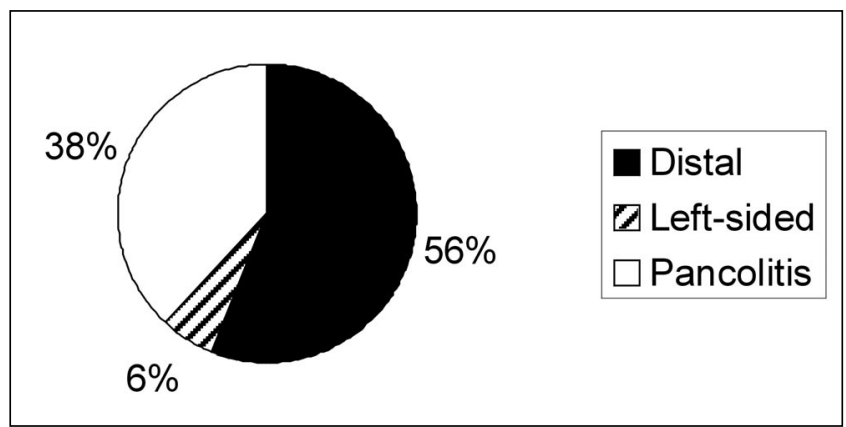

Figure 4) Distribution of disease in the gastrointestinal tract of patients with ulcerative colitis

and in Figure 3 for CD. The ranges in age of onset and duration of disease for $\mathrm{CD}$ and $\mathrm{UC}$ are summarized in Tables 1 and 2.

A large majority of UC patients had distal inflammation (Figure 4). In contrast, the minority of $\mathrm{CD}$ in the gastrointestinal tract was classified as distal colitis (Figure 5).

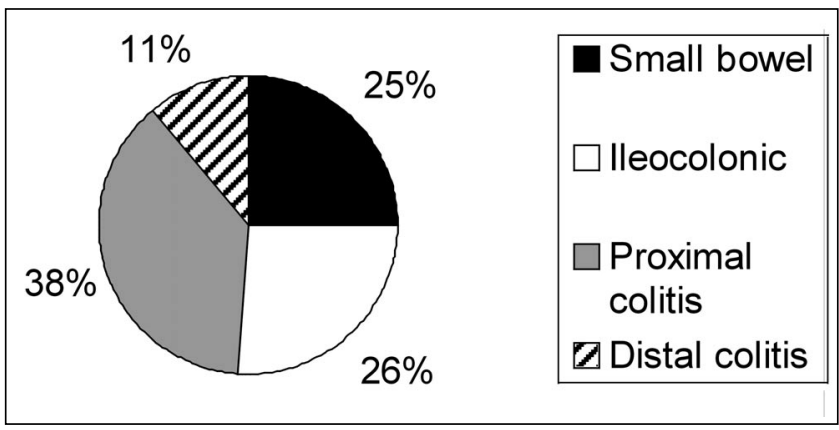

Figure 5) Distribution of disease in the gastrointestinal tract of patients with Crohn's disease

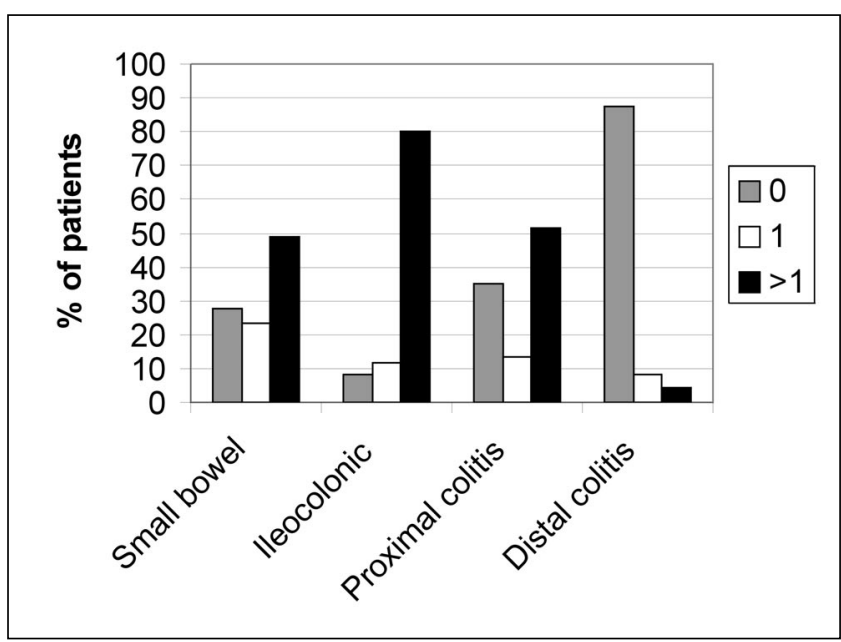

Figure 6) Courses of systemic steroids prescribed for patients with Crohn's disease, classified by disease location

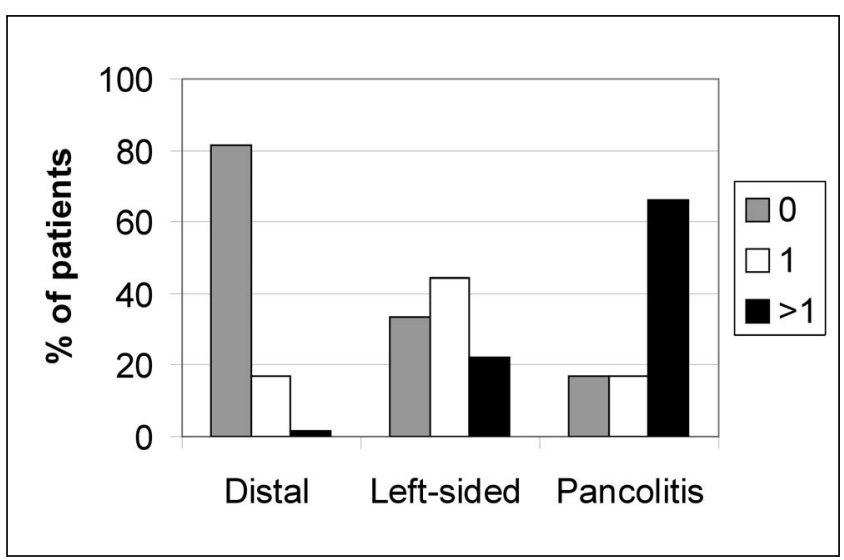

Figure 7) Courses of systemic steroids prescribed for patients with ulcerative colitis, classified by disease location

The need for systemic steroid therapy varied among diseases and disease locations. The data for $\mathrm{CD}$ and $\mathrm{UC}$ are summarized in Figures 6 and 7, respectively. In UC, over $80 \%$ of patients with distal disease did not require systemic steroid treatment. In contrast, only $17 \%$ of pancolitis patients did not require systemic steroids, while $66 \%$ required 


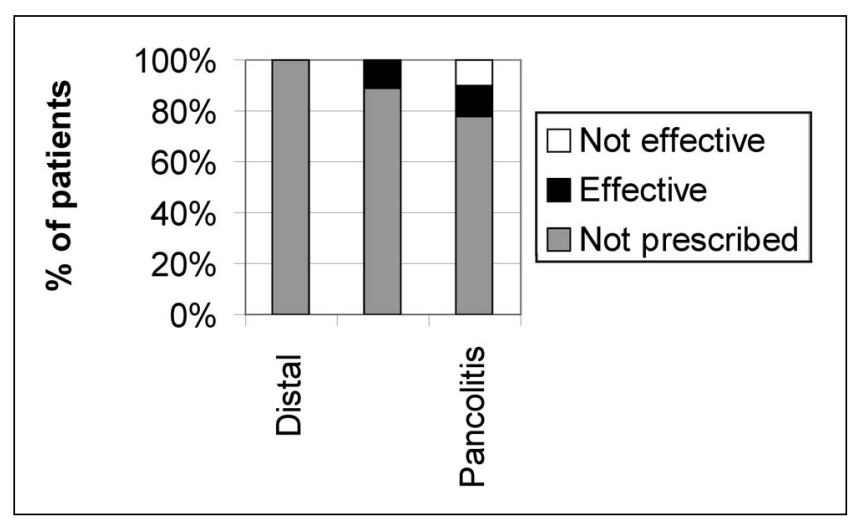

Figure 8) Need and effectiveness of immunosuppressants in patients with ulcerative colitis, classified by disease location

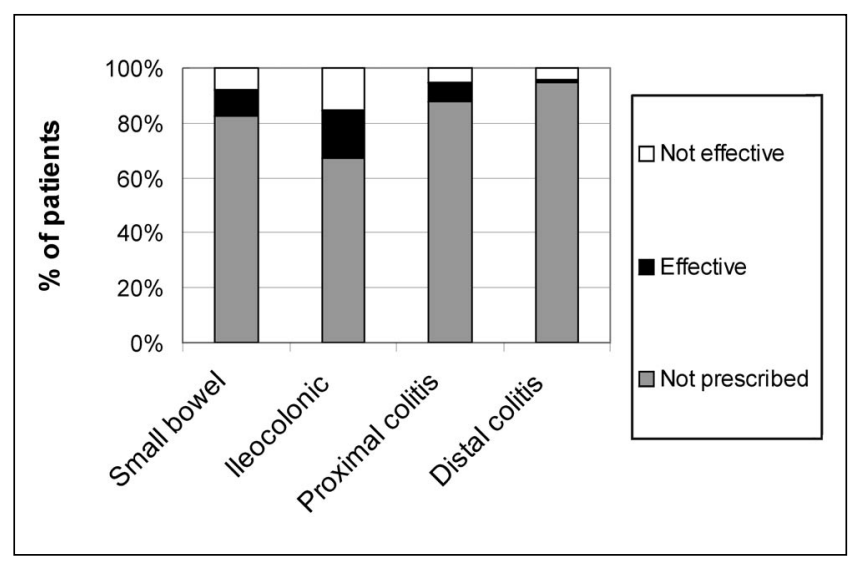

Figure 9) Need and effectiveness of immunosuppressants in patients with Crohn's disease, classified by disease location

more than one course. Of the CD patients, $80 \%$ with ileocolonic disease underwent multiple courses of systemic steroid therapy, whereas $87.5 \%$ with distal colitis did not require any such treatment.

Immunosuppressant therapy was not prescribed for any of the patients with distal UC, but was prescribed for patients with left-sided UC and pancolitis (Figure 8). All patients with left-sided UC responded well to the treatment, whereas only half of the patients with pancolitis responded well. Among the CD patients, $99 \%$ of those with distal colitis did not require immunosuppressants, whereas $32 \%$ of those with ileocolonic disease received such therapy (Figure 9). Of that $32 \%$, only about half of the patients benefited from the drug.

Only $10.4 \%$ of all UC cases required surgery (Figure 10). None of the patients with distal UC required an operation. Of the patients with pancolitis, $25.5 \%$ required surgery. The indications that led to surgical treatment within this $25.5 \%$ were refractory disease $(89.4 \%)$, toxic megacolon $(5.1 \%)$ and dysplasia (5.5\%). Only one patient with left-sided UC underwent surgery ( $11 \%$ of all patients with left-sided UC). The indication in this case was refractory disease.

In CD (Figure 11), surgical intervention was highest in patients with small bowel disease, with $81 \%$ undergoing at least one operation during the course of the disease. The in-

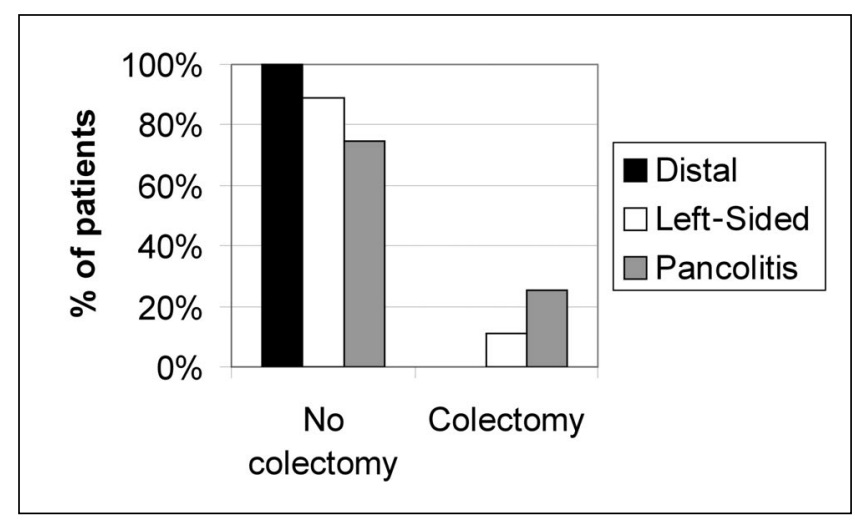

Figure 10) A comparison of the need for colectomy in patients with ulcerative colitis according to distribution of disease

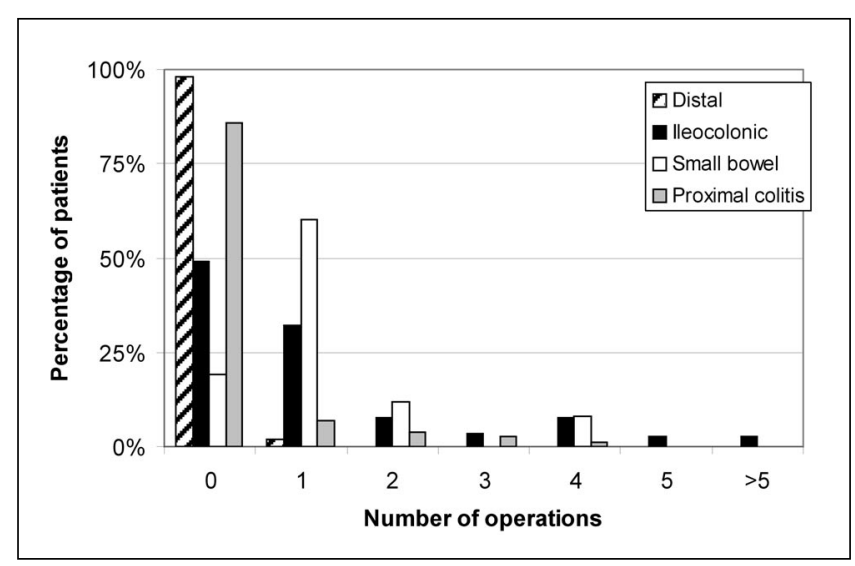

Figure 11) A comparison of the number of operations in patients with Crohn's disease, according to distribution of disease

dications that led to surgery in that $81 \%$ were obstruction (59\%), fistula $(9.1 \%)$, abcess $(9.1 \%)$, perforation (11.4\%) and intractable disease (11.4\%). Of all CD patients with proximal colitis, $14.5 \%$ required at least one operation. Indications for surgery in these patients were refractory disease $(69.6 \%)$ and stricture (30.4\%). Of the CD patients with distal colitis, only $2 \%$ needed an operation. The indication for these surgeries were fistula and refractory disease. Of CD patients with ileocolonic disease, $51 \%$ had at least one operation. The indications for surgery in this $51 \%$ were obstruction $(58.3 \%)$, fistula (13.9\%), abcess $(11.1 \%)$, perforation $(11.1 \%)$ and intractable disease $(5.6 \%)$.

Colectomy and ileostomy was performed in $3 \%$ of the CD patients and $4 \%$ of UC patients. Ileal pouch-anal anastamoses (IPAA) was performed on 7\% of the UC patients. Only $8 \%$ of CD patients with distal inflammation ever required admission to hospital, whereas $48 \%$ of CD patients with pancolitis required at least one hospital admission. In contrast, $80 \%$ of patients with small bowel CD required at least one hospital admission, whereas $51 \%$ of patients with ileocolonic $\mathrm{CD}$ required at least one hospital admission. Only $4 \%$ of patients with distal Crohn's colitis required admission, whereas $36 \%$ of patients with proximal Crohn's colitis required admission. 
Yearly surveillance for cancer was conducted in $25 \mathrm{UC}$ patients (with pancolitis and left-sided colitis) who had the disease for 10 or more years. The average duration of disease in these patients was 14.7 years, with a range of 10 to 36 years. No cancer was noted in any of these patients. However, one case of significant dysplastic change was observed in a patient with pancolitis in the 10th year of surveillance. This patient with dysplasia underwent colectomy after discovery.

\section{DISCUSSION}

The ratio of CD to UC patients observed in the study mirrored ratios observed by other investigators (4). However, the age of onset in our patient population did not show the bimodal distribution reported by others (5); only one peak was observed at the 20- to 29-year age range. The absence of a peak in the 60-year age group may be due to the relatively small sample size. Although the bimodal distribution was not observed, the mean age of onset for our $\mathrm{CD}$ and $\mathrm{UC}$ patients still agreed with those found in the literature $(5,6)$.

The distribution of CD and UC in the gastrointestinal tract only in part mirrored the published results $(4,7)$. In CD patients, the small number of distal colitis cases was consistent with results found by Schofield et al (7), who found only $12.5 \%$ of CD inflammation to be distal. The involvement of the small bowel alone in CD was also similar to results of Simsek and Schuman (4).

However, the large majority of distal inflammation observed in UC was not echoed in the literature, the closest figure being cited by Schofield et al (7) at 40\% and Hendriksen et al (8) at $41 \%$. Hendriksen et al (8) also reported a significantly lower percentage of patients with pancolitis (16\%) than was found in the present study (38\%).

The requirements for surgical intervention were strikingly similar between $\mathrm{CD}$ and $\mathrm{UC}$ and among the principal sites of disease. Of UC and CD patients, only one of 110 of patients with distal colonic disease required surgery. This result was also noted in work by Schofield et al (7). These results can aid a physician in counselling a patient with distal IBD as to the likelihood of surgery during the course of the disease. In CD patients, the highest rate of surgery was for inflammation of the small bowel, with $80 \%$ of cases requiring at least one operation. This finding coincides with results reported by Schofield et al (7), who reported an operation rate of $86 \%$. Analysis of the data from our study shows that CD is much more likely than UC to require surgery and that, of the different disease locations of $C D$, surgery seems to be performed least frequently for distal colonic involvement. Another study has shown that patients with CD ileocolitis for five years have a $75 \%$ chance of requiring surgery (9). We found that patients with CD ileocolitis had a $51 \%$ chance of requiring surgery. The trend seems to be that involvement of the small bowel is more likely to require surgery. Our findings tend to support this notion because $80 \%$ of patients with Crohn's colitis did not require an operation. In our study, only $10.4 \%$ of patients with UC required surgery. This observation agrees with results obtained by the Mayo clinic (10).
However, CD patients in our study had surgery at a much higher rate (38\%), reaffirming the increased morbidity of CD. Overall, of the 373 IBD patients, 74\% did not require surgery at all, reflecting findings published in other articles (11).

Hospital admissions reflected more severe disease and often the need for surgery. Patients with distal disease rarely needed surgery; this was shown by the fact that none of the distal colonic CD patients and only $8 \%$ of patients with distal UC were ever admitted to hospital. A large number of patients $(63 \%)$ with proximal colonic CD also were managed solely in an outpatient setting. Overall, $15 \%$ of UC patients and $31 \%$ of CD patients required at least two hospital admissions. These values are below those reported by others (12) but nevertheless illustrate that $\mathrm{CD}$ remains the more severe of the two diseases. Overall, $61 \%$ of IBD patients did not have any admissions, which exceeds values cited elsewhere in the literature (11).

The data for systemic steroid therapy also showed a relationship between severity of disease and disease location. Consistent with the other parameters measured, patients with distal disease, be it CD or UC, needed systemic steroid treatment much less frequently than patients with involvement of the small bowel or extensive large bowel disease. For UC, the numbers are quite convincing, with only $20 \%$ of patients with distal UC requiring systemic steroids compared with $83 \%$ of patients with pancolitis needing systemic steroids. Patients with left-sided UC fell between these two values; they needed systemic steroids in $67 \%$ of cases. This series of values nicely depicts the increasing need for treatment with increasing involvement of the bowel in the disease process. Of patients with CD, only $12.5 \%$ with distal colitis required systemic steroids compared with $91.7 \%$ with ileocolonic disease. This again shows the increased severity of disease with increased involvement of the bowel. When the data for immunosuppressant therapy are examined, the same pattern emerges. Distal colonic disease has a much brighter prognosis than pancolitis or small bowel involvement.

Of the CD patients, only $5.2 \%$ of patients with distal colitis received immunosuppressants compared with $17.8 \%$ with small bowel disease and $32.7 \%$ with ileocolonic disease. Of the UC patients, no patient with distal disease required immunosuppressant therapy, whereas $11 \%$ of those with leftsided disease and $22 \%$ of those with pancolitis had such treatment. Furthermore, of the patients with left-sided disease, all responded well to immunosuppressants. However, only about half of the patients with pancolitis responded well.

The absence of any cancer over the course of the surveillance for long standing pancolitis UC was not consistent with other sources that have cited rates of 3\% (11) and 1\% (8) for cancers in UC. The increased risk of developing cancer in long standing UC has been well documented (13-15). An incidence of $0.7 \%$ is expected in patients with pancolitis for a 10-year period (14). The relatively small sample size of our population is the most likely explanation for why none of our patients developed carcinoma. 
Comparing the counts for ileostomies and IPAAs, we see a similarity in IPAAs but a divergence in ileostomies. In our study, the frequency of IPAA in UC patients was $7 \%$ compared with $4.5 \%$ reported in the literature (11). The percentages of ileostomies performed in CD and UC patients in our study were $2.7 \%$ and $3.9 \%$, respectively; rates of $6.2 \%$ and $11.3 \%$, respectively, were reported in the literature (11). The difference in the frequency of the IPAA is small, but the divergence in values in ileostomies is quite large. This dichotomy may be attributed to a difference in aggressiveness in the treatment of the disease or to an increased number of elderly in the study by Andrews et al (11). A population with a large number of elderly (in whom IPAA is usually ruled out) would bias the course of action toward ileostomy

\section{REFERENCES}

1. Lennard-Jones JE, Lockhart-Mummery HE, Morson BC. Clinical and pathological differentiation of Crohn's disease and proctocolitis. Gastroenterology 1968;54:1162-70.

2. Yoon CM, Kim SB, Park IJ, et al. Clinical features of Crohn's disease in Korea. Gastroenterol Jpn 1988;23:576-81.

3. Nugent FW, Kolack PF. Differential diagnosis of chronic ulcerative colitis and Crohn's disease of the colon. In: Kirsner JB, Shorter RG, eds. Inflammatory Bowel Disease. Philadelphia: Lea \& Febiger, 1988:32.

4. Simsek H, Schuman BM. Inflammatory bowel disease in 64 black patients: Analysis of course, complications, and surgery. J Clin Gastroenterol 1989;11:294-8.

5. Sinclair TS, Brunt PW, Mowat NAG. Non-specific colitis in Northeastern Scotland: a community study. Gastroenterology 1983;85:1-11.

6. Binder V, Hendriksen C, Kreiner S. Prognosis in Crohn's disease based on results from a regional patient group from the county of Copenhagen. Gut 1985;26:146-50.

7. Schofield PF, Manson JM. Indications for and results of operation in inflammatory bowel disease. J R Soc Med 1986;79:593-5.

8. Hendriksen C, Kreiner S, Binder V. Long term prognosis in ulcerative colitis - based on results from a regional patient group from the county of Copenhagen. Gut 1985;26:158-63. because that would be the only other choice in a colonic resection.

In summary, in a community hospital practice, the site of disease seems to dictate the severity of the condition and the need for hospitalization, surgery, immunosuppressants and systemic steroid therapy. The large majority of patients with UC tend to have distal disease and are managed as outpatients, often not needing immunosuppressants and systemic steroids. Of the CD patients, those with small bowel involvement have the highest probability of needing medical therapy as well as hospital admission and/or surgery. These observations may provide helpful insights into designing prospective trials that reflect outcome and therapy for the IBD patient population in the community.

9. Whelan G, Farmer RG, Fazio VW, Goormastic M. Recurrence after surgery in Crohn's disease: Relationship to location of disease (clinical pattern) and surgical indication. Gastroenterology 1985;88:1826-33.

10. Van Heerden JA, McIlrath DC, Adson M. The surgical aspects of chronic mucosal inflammatory disease (chronic ulcerative colitis). Ann Surg 1978;187:536-41.

11. Andrews JM, Norton I, Dent O, Goulston K. Inflammatory bowel disease: a retrospective review of a specialist-based cohort. Med J Aust 1995;163:133-6.

12. Primatesta P, Goldacre MJ. Crohn's disease and ulcerative colitis in England and the Oxford record linkage study area: a profile of hospitalized morbidity. Int J Epidemiol 1995;24:922-8.

13. Ekbom A, Helmick C, Zack M, Adami HO. Ulcerative colitis and colorectal cancer. A population based study. N Engl J Med 1990;1228-33.

14. Gyde SN, Prior P, Allan RN, et al. Colorectal cancer in ulcerative colitis: A cohort study of primary referrals from three centres. Gut 1988;29:206-17.

15. Lennard-Jones JE, Melville DN, Morson BC, Ritchie JK, Williams CB. Pre-cancer and cancer in extensive colitis. Gut 1990;31:800-6. 


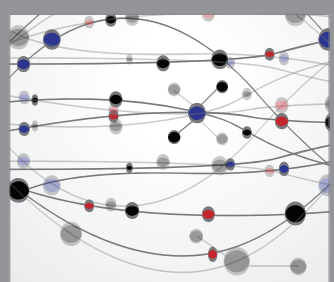

The Scientific World Journal
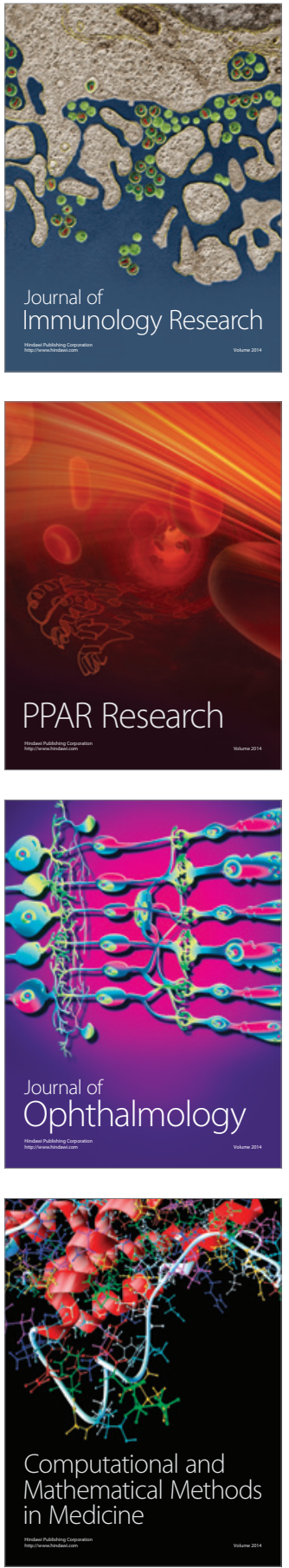

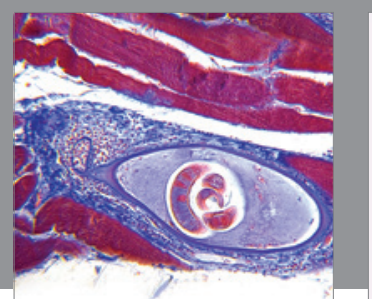

Gastroenterology Research and Practice

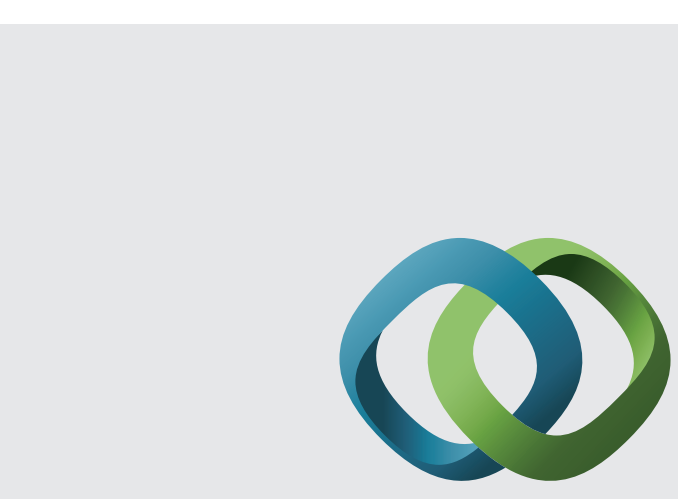

\section{Hindawi}

Submit your manuscripts at

http://www.hindawi.com
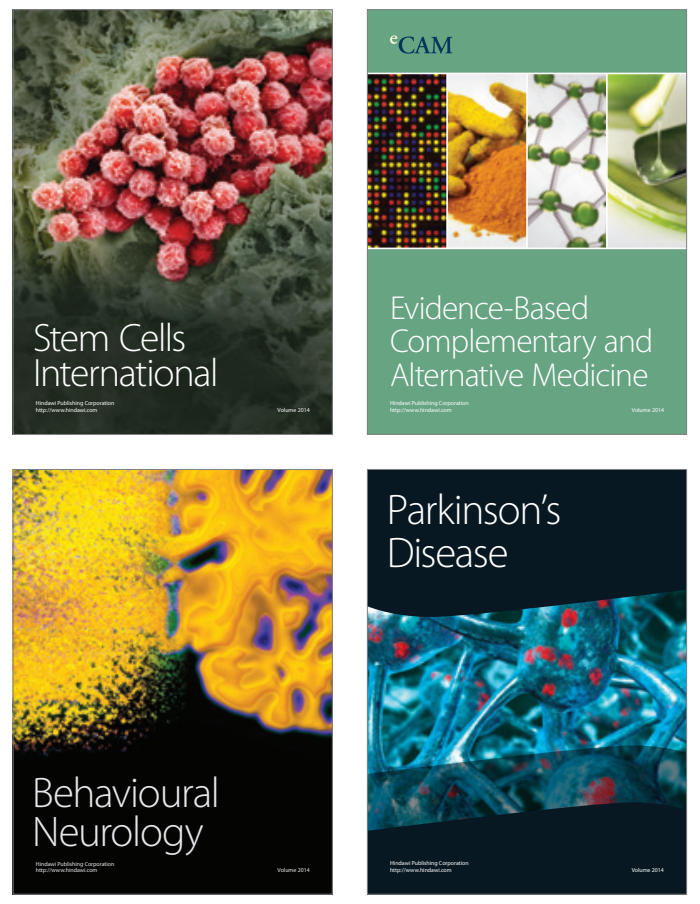
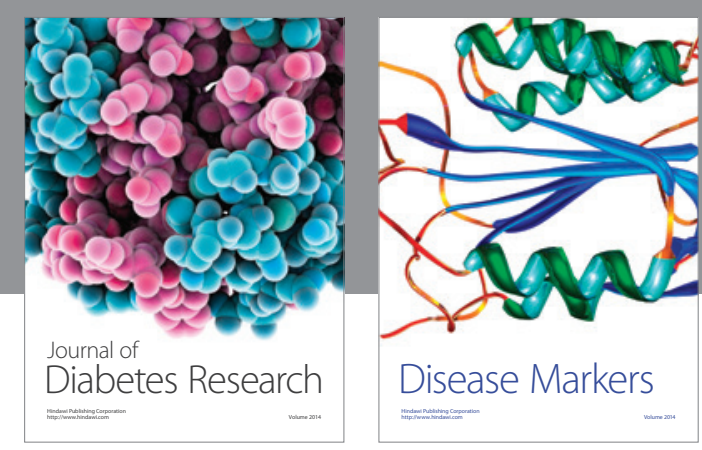

Disease Markers
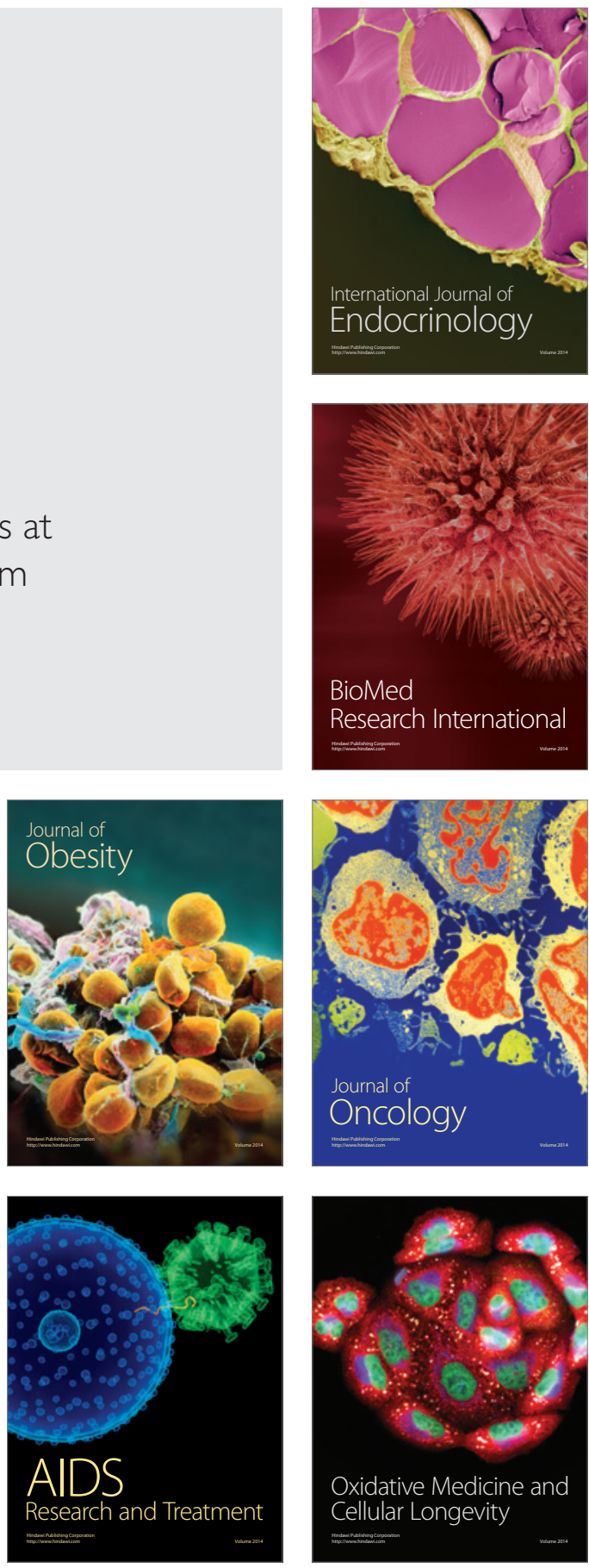